Jelena Anđelković ${ }^{*}$, Jelena Filipović

${ }^{1}$ University of Belgrade, Faculty of Organizational Sciences, Serbia 'University of Belgrade, Faculty of Philology, Serbia

\title{
Management and Leadership in Serbian Terminology Work
}

DOI: 10.7595/management.fon.2018.0025

\begin{abstract}
Research question: This paper studies the roles of Terminology Leadership (Filipovic 2012, 2015; Filipovic \& Vuco, 2012; Filipovic \& Djordan, 2018) and Terminology Management model (Jernudd \& Neustupny, 1987, 1991; Jernudd 1993, 1997 in Antia, 2000, p.3; Spolsky, 2004, 2009, 2012) in the implementation of terminology policy and planning in Serbia, and the sustainable development of Serbian scientific and technical terminology. Motivation: As in almost all standard-language cultures (Quirk,1990), the Serbian language policy is top-down oriented, i.e., it follows the language management model. In this model, all decisions regarding the language, including terminology decisions, are made by linguists - language planners, without taking into account the opinions of professional and academic communities, i.e., the primary creators and users of terminology. Newer European terminology guidelines, especially the widely accepted UNESCO Guidelines for Terminological Policies (2005, p.3), however, propose that terminology work should be approached both top-down, i.e., on the level of political decision-making (following the terminology management model), and bottom-up, i.e., on the level of professional associations and other terminology stakeholders (following the complementary model of terminology leadership). Idea: The idea behind this paper is to investigate to what extent the terminology leadership model and the bottom-up orientation in the Serbian terminology policy and planning are recognized and accepted by various groups of stakeholders in comparison with the dominant language management model. Data: The data regarding the perspectives of two groups of terminology stakeholders (technical translators and professional / academic community) towards the state of the Serbian subject-field terminology and terminology management were collected, analyzed, interpreted and compared. Tools: The data were collected through two surveys on terminology work (Andjelkovic, 2018). While the first survey focuses on translators' perspective on terminology management, the second survey examines the attitude of the academic community towards the terminology state of their own subject field: management. Findings: The surveys' results confirm that both groups of terminology stakeholders recognise the importance of collaborative and cooperative work of linguists and subject field specialists in terminology policy making, planning and implementation, and thus do not regard linguists (i.e., language planners) as exclusive language and terminology decision-makers. The results also indicate, however, that there is still a very strong influence of standard-language ideology and the top-down oriented language policy. Contribution: The paper suggests a change in the implementation of the Serbian terminology policy and planning that is more in line with the European terminology Guidelines (UNESCO, 2005).
\end{abstract}

Keywords: terminology management, terminology leadership, terminology policy and planning, adaptive leadership, enabling leadership, administrative leadership.

JEL Classification: Y8, O2, Z0

\section{Introduction}

Scientific and technical terminology represents the most important component of the language for specific purposes and can be considered a strategic resource of key importance for professional communication, information, and knowledge transfer. That is why terminology today is a significant topic of scientific research in the fields of linguistics, translation theory, language and terminology policy and planning, know- 
ledge management, information science, computational linguistics, natural language processing, etc. Bearing in mind the constructivism approach to science of the late 20th and early 21 st centuries that erases boundaries between scientific disciplines and advocates a trans-disciplinary approach to the creation and use of academic resources in general, and terminology resources as well (Filipovic, 2015), terminology is nowadays mostly studied within interdisciplinary and transdisciplinary studies.

Scientific and technical terminology development is closely related to the socio-economic situation in the modern world, i.e., to economic, financial, and cultural globalisation, the rapid development of information and communication technologies, the global status of English as the international lingua franca (Clyne \& Sharifian, 2008), and the growing contrast between the developed and developing economies and markets. Namely, economically and technologically developed, dominantly English-speaking, markets and economies have turned the English language into the dominant language of professional and scientific communication and the main provider of terminology worldwide, especially in rapidly growing subject-fields and disciplines. This resulted in the globalisation and internalisation of terminology, justified by the need for efficient and effortless international communication. This process, however, also created significant terminology and communication problems in non-English languages of developing countries, especially in languages of lesser diffusion (Piper, 1998; Bugarski, 2003) and their respective emerging economies and markets. As a countebalance to terminology globalisation, these countries and languages emphasize a need for localisation, i.e., translation, creation, and adaptation of terminology for the purpose of its maintenance in the language in question (Schaffner, 1999). Localisation is thus aimed at preserving the diversity, functionality and sustainable development of individual specialised languages for the dissemination and transfer of specialized knowledge and information.

In order to preserve the functionality of a language in its professional domains of use and ensure its sustainability, a country requires a responsible and systematically implemented language policy and planning (LPP), and terminology policy and planning (TPP) as an integral part of corpus language policy in particular (Filipovic \& Djordan, 2018; Jakic, 2014). In this paper, the Serbian language terminology is viewed from the perspective of terminology policy and planning, with the aim of establishing the roles of terminology management and terminology leadership models in TPP formulation and implementation.

The following sections of this paper define the concepts of language policy and planning (LPP), terminology policy and planning (TPP), language and terminology management, as well as language and terminology leadership, with a particular focus on the ambiguity of the term terminology management in the strictest and in the widest sense. Further in this paper, results of two questionnaires focusing on the Serbian terminology work, authority and cooperation will be provided, with the aim of discovering to what extent the terminology management and terminology leadership models are represented in terminology policy and planning implementation in the Republic of Serbia.

\section{Management and Leadership in Language and Terminology}

\subsection{Language policy and planning (LPP), language management, and language leadership}

Language policy and planning (hereinafter referred to as LPP) is often defined as "organized, targeted and long-term activity of state institutions on various aspects of the status, form, and domain of use of a particular language variant" (Filipovic, 2009, p.54). LPP "is never independent of political, economic, and social theory" (Ricento, 2006, p.19), i.e., it is always influenced by macro-sociopolitical processes and events, epistemological paradigms, and strategic goals (Ricento, 2006, p.26; Filipovic, 2009, p.55).

The definitions stated above refer to the top-down oriented LPP, in which all the decisions regarding the selection of a linguistic variant to be standardized (status $L P P$ ), the language structures, forms and vocabulary to be processed (corpus $L P P$ ) and the varieties to be used in education (educational LPP) are made by authorized institutions and entities (Filipovic, 2015, p. 44). The top-down orientation in language policy and planning is typical of standard-language cultures (Milroy, 2001; Filipovic, 2009; 2012; 2015), i.e., language communities in which the standard language is regarded as the main carrier of national and individual uniqueness (Filipovic, 2015, p. 47). Under the strong influence of the standard language culture, the Serbian language and its terminology have been viewed as the responsibility of linguists, i.e., top-down oriented language planners (Filipovic \& Djordan, 2018), indifferent to real life language practices and speakers' communicative needs and any bottom-up oriented terminology and language policy and planning (Filipovic, 2015, p. 47). 
This traditional top-down LPP orientation is associated with a more contemporary Language Management paradigm (introduced by Jernudd \& Neustupny, 1987, 1991; Jernudd, 1993, 1997 in Antia, 2000, p.3, and further elaborated by Spolsky, 2004, 2009, 2012). This paradigm transferred the focus from the planning model to the management model (Jernudd, 1993, p.134 in Antia, 2000, p. 3), and applied management concepts and terms to linguistic research and language policy (Spolsky, 2009 in Filipovic, 2015, p. 44).

In the language management model, the role of a language manager is of crucial importance. In standard-language cultures, the role of a language manager is performed by an authoritative national institution that imposes language rules and decisions, introduces prescriptive measures and publishes language manuals (Spolsky, 2004, p. 8). Filipovic and Vuco (2012, p. 9) define language managers as individuals, institutions or countries whose activities directly correlate with certain sociopolitical, epistemological and strategic interests of political entities. In management science, a manager is superior to other members of the organization, and in case of language, a language manager is superior to other members of society, language or professional community (Filipovic, 2015, p. 45). The top-down orientation advocated by the language management model is to some extent problematic since it fails to recognize the facts that language change is inseparable from social change, and that a language needs to adapt to communicative, social, psychological, cultural, and professional needs of certain social groups and communities (Filipovic, 2015, p. 48-49). These facts imply that a language policy also needs to be implemented bottom-up, which leads to an alternative (and complementary) model of language leadership (Filipovic, 2015).

The concept of leadership has been adopted from the Complexity theory (Uhl-Bien et al., 2007, Wheatley, 2004, Zenousi \& Dehghan, 2012; Byrne, 2002), a comprehensive epistemological paradigm that opposes the hierarchical scientific methods of positivist and structuralist orientation. In linguistic research human organizations are also defined as complex systems, and the concept of language leadership, interpreted from a macro-complexity perspective, is successuflly applied to language policy and planning (Filipovic, 2015, pp. 29-30). Witin the language leadership model, the hierarchical relationship that managers have towards other members of the community (top-down orientation) is replaced by a heterarhic structure, partnership, teams, and networking (bottom-up orientation) (Whitley, 2004, pp. 13-14). Language leaders, unlike language managers, act as initiators or motivators who do not use their formal positions of power to impose certain language patterns and practices and pressure others to use them too (Filipovic, 2015, p. 5) but still influence language behaviour of others because of the respect and positive attitude that other members of the community have towards them (Filipovic, 2015, p. 46). Those members of language communities and / or professional communities that introduce emergent language behaviour (new forms resulting from the fulfillment of communication needs) are regarded as adaptive language leaders. Individuals who spread this language behaviour beyond their own language community, through interaction with external members, are enabling language leaders. Since the emergent language practice sometimes does not follow the dominant language ideology, the introduction of such practices sometimes implies significant language and social changes, and often encounters disapproval of those outside the given community (Eckert \& McConnellGinet, 1992). In the event that the approval is nevertheless reached, language managers give way to administrative language leaders, who, unlike managers, work closely with enabling language leaders (Filipovic, 2015, p. 40). The terminology policy and planning model that will be outlined in the sections below is based on the language leadership model.

\subsection{Terminology policy and planning (TPP), terminology management and terminology leadership}

Terminology policy and planning (hereinafter referred to as TPP), as an integral part of a national language corpus policy and planning, is concerned with the strategies for development and regulation of terminology and terminology systems of professions and sciences in the given language, i.e., political decisions and interventions aimed at the conscious, systematic and sustainable development of the language for specific purposes and its terminology. The basic goal of terminology planning is the fulfillment of communication needs in scientific and professional domains and the provision of intra-lingual and inter-lingual communication in languages for specific purposes. Terminology planning is, however, often done purposely, i.e., decisions regarding terminology planning can actually be a tool for achieving socioeconomic transformational policies (UNESCO, 2005, p. 6).

Although there is a general consensus that the TPP should be based on a predefined model, it seems that there is no single TPP model that would be fully applicable to all languages without adapting it to their respective socio-cultural and socio-political circumstances. A possible exception may be the UNESCO Guidelines for Terminological Policies: Designing and Implementing Terminology Policy in Language 
Communities, formulated in cooperation with the international terminology organization Infoterm in 2005 , as well as the international standard ISO 29383:2010 Terminology policies - development and implementation. These two documents set out the general framework of the terminology policy and planning model, advocating a conscious, systematic, and controlled approach to the creation, maintenance, and use of terminology for the purpose of its sustainable development within a language community. The UNESCO Guidelines state that strategic decisions on terminology policy should be made top-down, i.e., on the level of political decision-making (with a recommendation that this policy be multilingual and non-restrictive), but they also claim that the TPP is created and implemented bottom-up, i.e., on the local level: in private companies, nongovernmental organizations, professional associations etc. (UNESCO, 2005, p. 3). In other words, terminology policy is not the sole responsibility of language planners (as is the case in almost all standard-language cultures), but it should also be dealt with by those members of professionaland academic communities who, for the sake of adequate communication, continually upgrade and change the conceptual and terminological systems of their professions. The UNESCO Guidelines may thus imply that terminology policy and planning should be imlemented in accordance with the language leadership, rather than with the language management model (explained above) to ensure sustainable development and maintenance of functionality of professional discourse and terminology in languages of lesser diffusion such as Serbian. Even though this paper observes terminology management as part of the language management model, it is important to note that terminology management is a somewhat problematic concept accross disciplines (in terminology science, terminology policy and planning, translation theory, computational linguistics and other disciplines, etc.). There are several reasons behind this.

When first used, the terminology management term labelled "every deliberate manipulation of terminological information" (Wright \& Budin, 1997, p. 1). By emphasizing the word management, these authors wished to highlight the importance of dealing with the quantity of information available to us in the modern world, and the importance of managing and controlling the information available (Wright \& Budin, 1997, p. 2-3). The same authors drew a parallel between terminology management and information management, as both of them are, in fact, total quality management tools. Terminology management activities, according to Wright and Budin (1997, p. 22-23), are as follows:

- Creating and naming new concepts, i.e., assigning terms to concepts in order to meet the need for a precise and unequivocal language for professional communication;

- Systematic recording of terminological information in dictionaries, terminology collections and databases;

- Use of terminology information for oral and written translation, technical writing and information management.

Over time, the range of activities, products, and resources attributed to terminology management has expanded to also include the following:

- Selection of terminological units for terminographic processing and / or standardization;

- Creation and exploitation of a wider range of primary and secondary terminological resources and products: language corpora for special purposes, printed and electronic terminology dictionaries, glossaries, lexicons, terminology databases and terminology knowledge bases (ontologies), terminology norms and other collections of terms;

- Development and exploitation of software tools and terminology management systems (TMSs);

- Provision of terminological services;

- Organization of terminological trainings, etc.

Due to the diversity of terminology activities, the role of terminology managers is performed by various stakeholders, i.e., the representatives of professional and academic communities, translators, translation agencies and translation departments in public, private and international companies, computational linguists and natural language processing (NLP) experts, but also by language planners and national and international language and standardization institutions, and many others. Terminology management is thus conducted on several levels: individual, local, national, and international, and is performed with diverse aims.

Having all the abovesaid in mind, we believe that terminology management can be observed in its strict and its wide senses.

Terminology management in its strict sense denotes the development and use of software solutions for terminology storage, i.e., terminology management systems (TMSs) as integral parts of computer-assisted translation tools (CAT) that contribute to the development of machine translation $(M T)$ systems, all directed towards technical translation and terminology localization. 
Thus, terminology activities undertaken by technical translators, translation agencies, and translation departments within larger organizations, public or private enterprises belong to terminology management in the strict sense. Translators employ various methods to collect and store terminology, create glossaries and internal termbases, lists of terms or terminology use, guidelines, and handbooks (Bucher, 2007, p.44; Fiser, 2008). These terminology storage methods not only accelerate and facilitate translation of technical texts, help with technical writing and assist in professional communication in general, but they also improve the consistency and quality of translation, at the same time keeping the price of translation lower. A number of commercially available software systems for terminology activities (Terminology Management Systems -TMSs) that can be used in translation and technical writing are available nowadays. These systems are most commonly integrated into CAT tools (Computer-Assisted Translation tools), along with translation memories (TMs). The most popular CAT tools are SDL Trados, OmegaT, and MemoQ (Gornostay, 2010). In order to promote their products, commercial software producers emphasize the benefits that terminology management systems bring to corporate users, particularly the fact that they contribute to a better understanding of relevant terminology by employees, prevent terminology errors in technical documentation, reduce the time of technical documents production, lower translation costs, and contribute to the consistency of translation (SDL software company). The fact is, however, that the number of organizations consistently and systematically engaged in terminology activities is still rather small, the most important reasons behind this being the lack of awareness of their importance, high costs of terminology manangement systems, and the fact that benefits are difficult to measure.

The fact is, however, that the number of organizations consistently and systematically engaged in terminology activities is still rather small, the most important reasons behind this being the lack of awareness of their importance, high costs of terminology manangement systems, and the fact that benefits are difficult to measure.

The Department for Communications, Training and Preparation of the Serbian Version of Acquis Communautaire within the Ministry of European Integration, Government of the Republic of Serbia, has recognized the importance of using terminology management software tools and systems. In order to achieve terminological consistency and quality of translation of the massive documentation necessary for the EU integration process for the Republic of Serbia, the Department has developed an electronic terminographic resource: the multilingual terminology database Evronim, with over 18,000 terminology units in Serbian and their English equivalents (sometimes along with equivalents in several other 15 European languages, including Latin). Along with Evronim, the Department is also in charge of Evroteka, a bilingual, English-Serbian collection of legal texts. The collection is aligned and represents a translation memory created using the SDL Trados tool, currently containing more than 100,000 words.

In its wide sense, terminology management is not an operational, but a sociolinguistic category that is a part of the top-down oriented language management (outlined above), concerned with strategic decisions and recommendations regarding terminology development, implementation of national terminology policies, and maintenance of national terminological infrastructures. In the wide sense, terminology management encompasses both both descriptive and prescriptive activities (Wright \& Budin, 1997, p.18), aimed at documenting and standardizing terminology used in a particular domain. These activities are organized, coordinated and systematically implemented by national terminology centres, language and standardization institutions with the purpose of harmonizing and standardizing terminology, and formulating and implementing terminological language policy and planning.

The term management within the phrase terminology management implies a hierarchical top-down relationship between national language and terminology institutions as the only strategic decision-makers regarding terminology, on the one hand, and the actual terminology users - members of professional and academic communities, on the other hand. In other words, terminology management in its widest sense does not acknowledge the importance of networking, mutual cooperation and interdisciplinary collaboration between all the terminology stakeholders: terminology and language planners, domain / subjectfield specialists, computational linguists, technical translators, etc. Lack of cooperation and partialised terminology activities would result in non-transparency and redundancy of terminology work. For this reason we believe that the concept of terminology management in its wider sense should be complemented by another concept, the one of terminology leadership.

Terminology leadership, in line with the concept of language leadership (outlined above), implies mutual cooperation, hierarchical relationship and interdisciplinary networking between all the terminology stakeholders, i.e., associations, institutions and individuals who create, edit, maintain, translate, use, and standardize terminology. 
Figure 1 represents the Terminology leadership model, proposed by Filipovic \& Djordan (2018), with all the terminology stakeholders classified into adaptable, enabling, and administrative terminology leaders. In this heterarchical relationship, adaptable terminological leaders are those members of professional or academic communities (i.e., subject field / domain experts) who introduce new terminology units into a language. A new terminology unit can be created either through the process of primary term formation, i.e., by designating a newly created concept in the source language, or through the process of secondary term formation, i.e., by translating or borrowing (with or without orthographic and morphosyntactic adaptation) the term created in the primary term formation process in the target language (Humbley, 2003, p.197). This aspect of terminology leadership is not limited to members of professional and academic communities, but is also quite often done by technical translators, when a term with no available translation equivalent is encountered. Enabling terminology leaders, on the other hand, are the ones who, through interdisciplinary dialogue and cooperation with members of other professional communities, verify the monosemy and adequacy of the given term or its translation into a target language. Finally, administrative terminology leaders are institutions that consist of linguists, translators and terminology planners, as well as members of other disciplines and professions (domain specialists), who work together on the harmonization, systematization and standardization of terminology of individual scientific and professional disciplines. The final, administrative, level of terminology leadreship thus also includes the activities of terminology management in its strictest sense, i.e., the creation of terminology resources, such as dictionaries, termbases, terminology portals and national terminology banks, which are inevitably performed in close cooperation between all the abovementioned stakeholders. Through networking and cooperation, the three types of terminology leaders jointly contribute to the effective terminology planning and responsible terminology policy implementation, while interdisciplinary cooperation and networking exist not only between, but also within all three levels of terminology leadership.

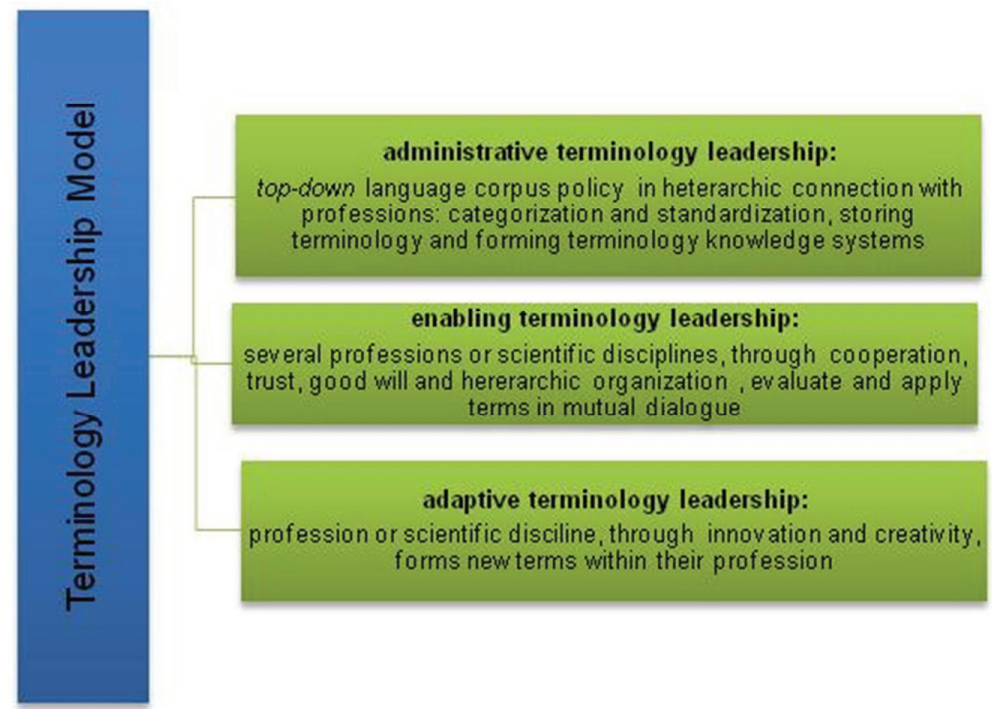

Figure 1: Terminology leadership model (adapted from Filipovic \& Djordan, 2018)

\section{Management and Leadership in Terminology Work}

\subsection{Terminology management in its strictest sense: translators' perspective}

A number of studies and surveys regarding terminology management in translation have been carried out. Most of the studies referred to the use of software tools and systems in translation, organizing and storing terminology by freelance translators, translation agencies and translation departments within large organizations (Fulford \& Granell-Zafra, 2005; Lagoudaki, 2006; Fischer, 2008; Gornostay, 2010, etc.). Some of the research (Gornostay, 2010) identifies lists of terms in Microsoft Excel and Microsoft Word as still the most popular ways of storing terminology for further use in translation. None of the above surveys, however, included translators or translation agencies from Serbia.

In order to discover the terminology management habits of Serbian translators, a small-scale study was conducted in the form of an online questionnaire (Andjelkovic, 2018). Fifty translators participated in the study: 22 (44\%) full-time freelance translators, 4 (8\%) translators working for translation agencies, $8(16 \%)$ in-house translators employed by various companies, $10(20 \%)$ foreign language teachers occasionally engaged in technical translation, $3(6 \%)$ professional terminologists, and $3(6 \%)$ respondents from other pro- 
fessions and with no formal education in foreign languages, but with experience in technical translation. The majority of respondents $(34$, or $68 \%$ ) had more than 10 years of translation experience, while only 5 respondents $(10 \%)$ had had been translating for less than three years. Most respondents (46, or $92 \%)$ translate from English. Other languages that the respondents marked were German, French, Italian, Russian, Slovene, Albanian, etc. (respondents were allowed to mark one or more languages).

When asked whether and how they store new terminology encountered in the translation process for further reference, only 11 out of 50 respondents $(20.75 \%)$ claimed that they do not manage or store it in any way. Most respondents, however, replied that they manage terminology by making lists of terms in MS Word (18 or $33.96 \%$ of respondents) or MS Excel (17 or $32.08 \%$ of respondents), while only 7 respondents (13.21\%) use terminology management systems (Figure 2).

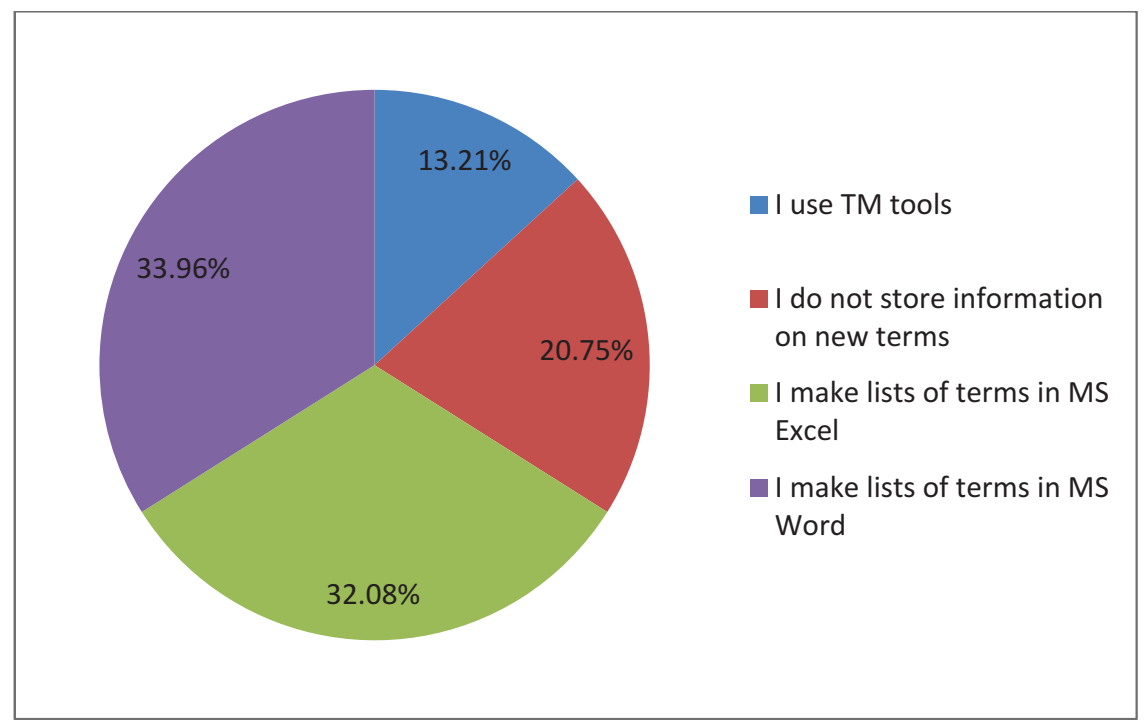

Figure 2: Terminology management habits of translators in Serbia

In order to discover to what extent terminology management is present in formal education of translators, the respondents were asked a closed question that referred to whether they had had a chance to learn about terminology management practice and tools during their formal education. Almost two thirds (34, or $68 \%$ ) of the respondents stated that they had not had any training in terminology management in schools and universities. A small number of respondents acquired this knowledge on their own through translation practice (11 or $22 \%$ ), while only three respondents (6\%) attended a seminar or a workshop on terminology management for translation purposes (Figure 3).

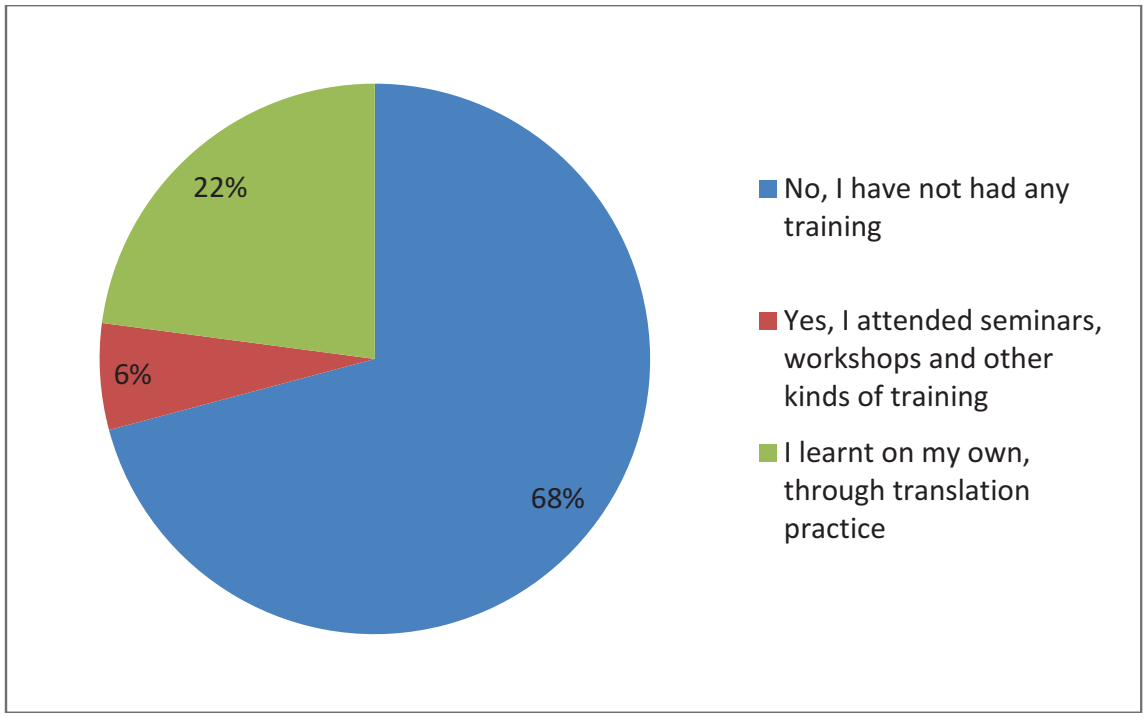

Figure 3: Terminology management in formal education of translators in Serbia 
In the next question, the respondents were asked how they resolved terminology translation dilemmas in case no available terminological resource provides an adequate translation equivalent. Respondents were asked to mark one or more out of four offered responses. Forty-one respondents $(82 \%)$ claim that they consult translation contractors, while 32 respondents (64\%) seek advice from other translators. Only 7 respondents $(14 \%)$ follow their own instinct when unsure of the appropriate translation of a term, while only two respondents (4\%) claim that they resolve terminological dilemma by consulting subject field experts who are not contractors of the given translation (Figure 4).

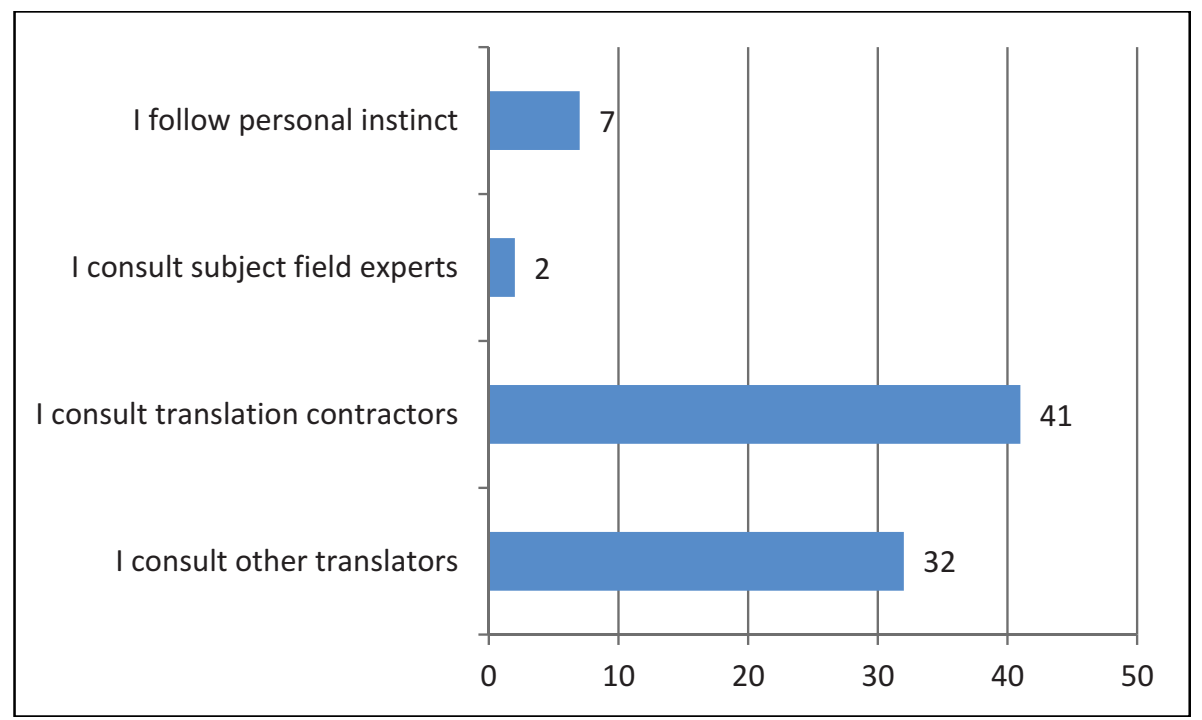

Figure 4: Cooperation in terminology management: translators' opinion

\subsection{Terminology management and leadership: professionals' perspective}

Another study (Andjelkovic, 2018), aimed at examining the state of Serbian terminology in the domain of management, provided some interesting results regarding the opinions of the academic community (about terminology activities and problems encountered in this domain, as well as the matter of terminological responsibility. A total of 48 respondents filled in the questionaire. All the respondents were members of the teaching staff at the study group of Management and Organization at the Faculty of Organizational Sciences, University of Belgrade, i.e., 4full professors, 6 associate professors, 6 assistant professors, and 34 teaching assistants.

When asked whether they believe there are terminology problems in the subject domain of management in the Serbian language, as many as $94 \%$ of the respondents have confirmed that they do exist.

$\square$ yes no $\square$ I do not know

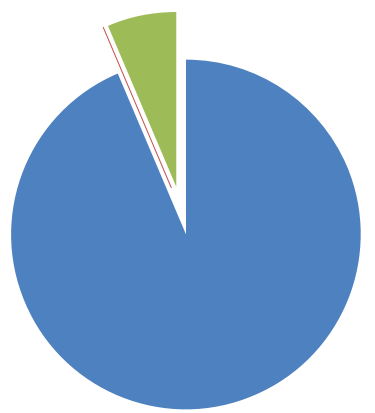

Figure 5: Are there terminology problems in the subject field of management in Serbian?

In the following question, the respondents were offered several terminology problems and asked mark them on a scale from 1 (most important) to 5 (least important). The most important problem, according to 42 respondents (or $87.5 \%$ ), is the lack of Serbian equivalents for foreign terms, followed by terminology depen- 
dence on the English language (38 respondents, or 79.17\%), non-standardized terminology (31 respondents, or $64.58 \%$ ), the lack of terminological resources (25 respondents, or $52.08 \%$ ), and terminology synonymy (22 respondents, or $45,83 \%)$.

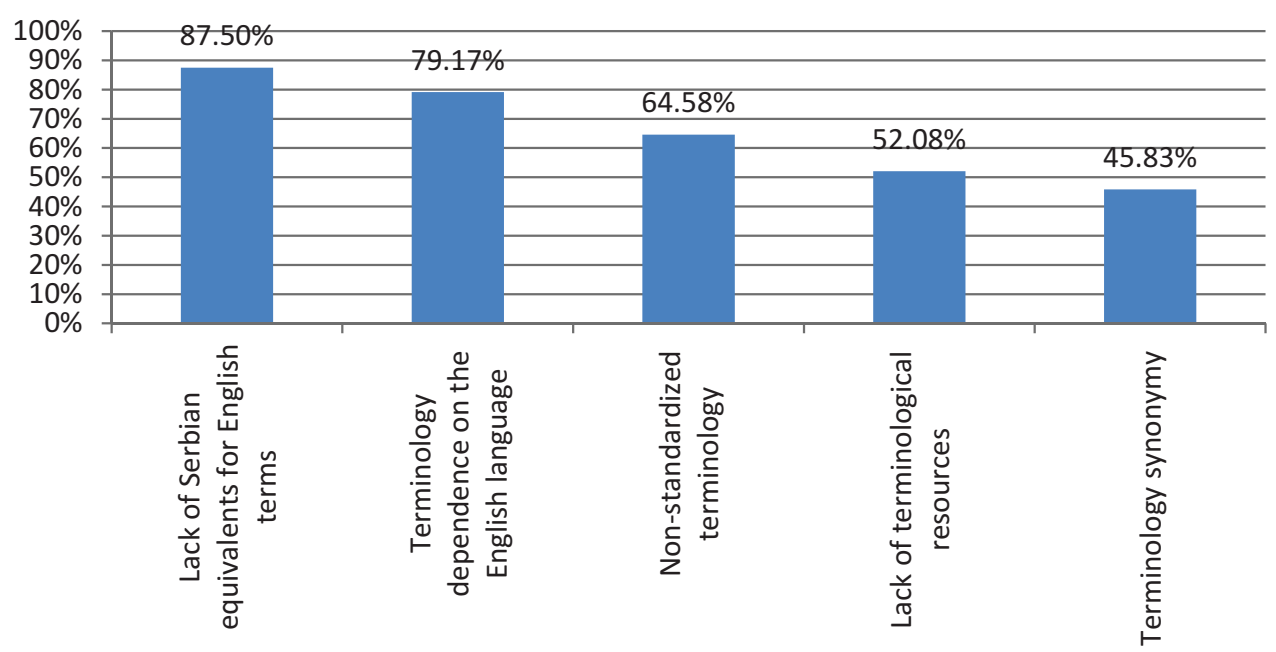

Figure 6: Types of terminology problems in the subject field of management

In a multiple choice question focusing on the responsibility for terminology management in its widest sense, the respondents were able to chose among three options: a) linguists, i.e., language planners, b) experts for the subject filed of management, and c) both. As many as 41 respondents $(85.52 \%)$ stated that management experts and language experts should share this responsibilty and act cooperatively when solving terminology issues. Only four respondents $(8.33 \%)$ claimed that terminology management (in the widest sense) was the sole responsibility of language experts, while only three of them (6.25\%) opted for subject field (i.e., management) experts.

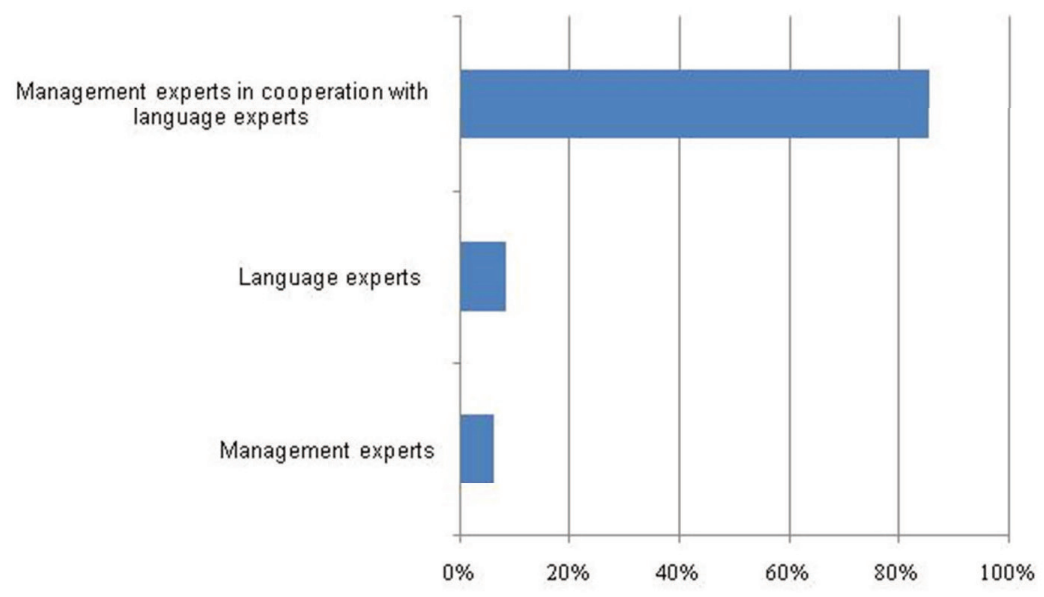

Figure 7: Cooperation in terminology work: subject field experts' opinion

The last question in the questionnaire focused on institutional foundations for terminology management in the Serbian language. In response to the multiple choice question about which institution(s) should be in charge of scientific and technical terminology for this particular subject field, 15 respondents (34.09\%) marked universities, i.e., faculties or departments which are parent to certain areas, while nine respondents (20.45\%) claimed that this should be the Institute for the Serbian Language within the Serbian Academy of Sciences and Arts. Seven respondents (16\%) marked several institutions, thus expressing their belief that cooperation between the aforementioned institutions is needed. An interesting fact is that as many as ten respondents $(22.73 \%)$ replied that the institution in charge should be a newly established centre for terminology (Figure 8). 


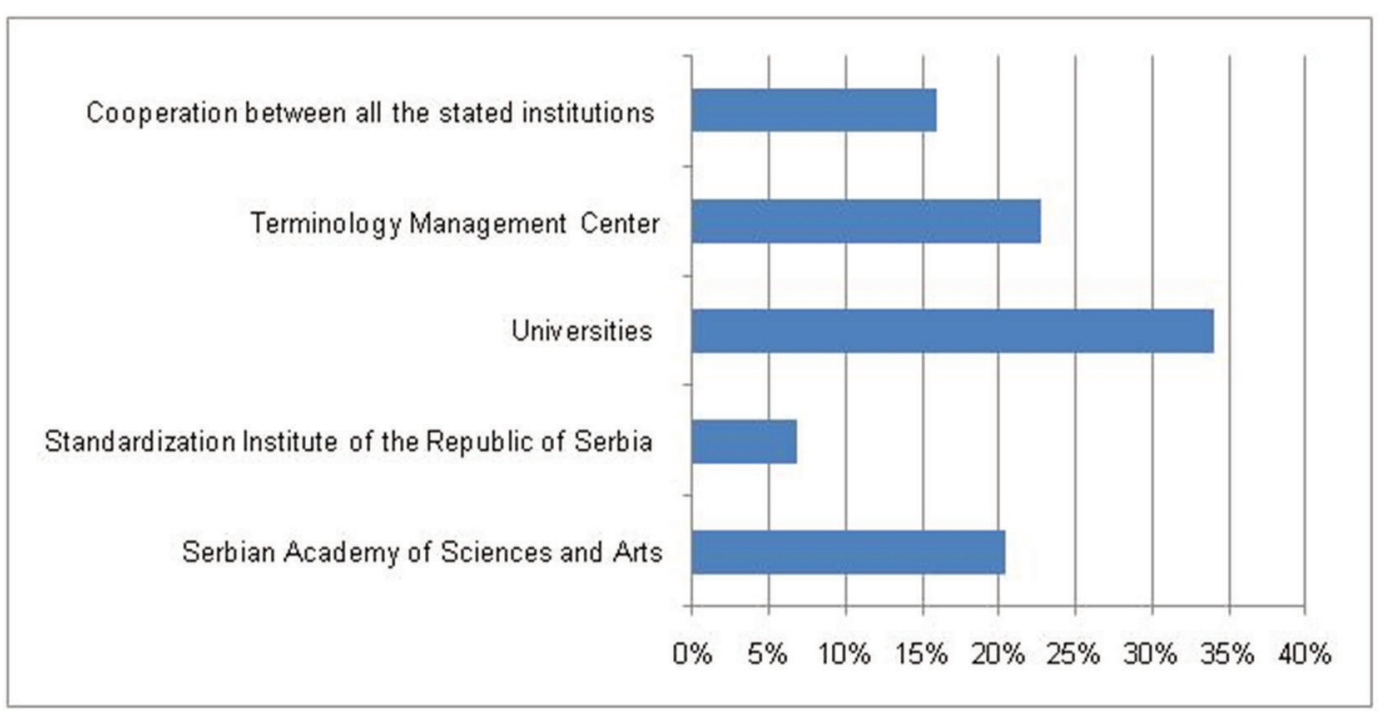

Figure 8: Serbian institutions responsible for TPP: subject field experts' opinion

\subsection{Diverse or similar perspectives on management and leadership in terminology: a discussion}

Sections 3.1. and 3.2. above provide an overview of the results of two questionnaires focusing on scientific and technical terminology in the Serbian language. Even though the two questionnaires share the overall topic and have a similar number of respondents, they differ in a number of ways. While the first questionairre targets translators and their perception of terminology management, i.e., terminology management in its strictest sense, the second questionairre is aimed at members of professional community (for the subject field of management) and their perception on how the terminology of their subject field should be managed, as well as on who should be in charge of this task. In other words, the second questionnaire observes terminology management in its widest sense.

The results of the two surveys can be observed independently, but they are also, despite the differences, to a certain extent comparable, while their comparison can lead to interesting conclusions.

The results of the first questionnaire indicate that terminology management trainings for translators (i.e., terminology management in its strictest sense) are lacking in Serbian formal education. Such statistics may indicate the need for organizing trainings and workshops in terminology work in order to raise awareness of its importance and the benefits it brings to quality and consistency of translation. In addition, the fact that most translators claim to consult subject field experts when faced with a terminology translation problem may indicate that they are very much aware of the importance of interdisciplinary networking and cooperation in terminology work.

The results of the second questionnaire confirm that subject field experts (i.e., members of academic community and management experts) are very much aware of the existence of terminology problems in their subject field. The majority of the respondents believe that the most important among these problems is the existence of terminology gaps in Serbian, as well as dependence on English and uncritical acceptance of English terms.

Another interesting finding is that the majority of the respondents to this questionnaire believe that language planners and subject field experts share the responsibility of managing terminology in their subject field. This may suggest that they are, similarly to translators, aware of the importance of transdisciplinary cooperation and teamwork on finding solutions to terminological problems in the field of management. In addition, the respondents in this questionnaire are rather divided regarding their view on which institution should be in charge of terminology planning (i.e., terminology management in its strictest sense); some of them also believe that this should be done cooperatively between several of the stated institutions. These findings indicate that the members of this academic community are fairly divided between accepting their own responsibility for terminology of their profesional domain and transfering the responsibility to (or sharing it with) an institution that exclusively employs linguists, and not experts in management, thus confirming the need for transdisciplinary cooperation discussed above. In other words, there seem to exist a mild opposition to the traditional top-down orientation in terminology planning (i.e., in terminology management in its 
widest sense) dominant in Serbia (Filipovic \& Djordan, 2018) in which terminology decisions are made by authorized language institutions and entities that employ solely linguists as language and terminology planners. Another orientation, bottom-up oriented terminology planning (Filipovic, 2015, p. 47) seems to be gaining pace, thus transferring Serbian terminology planning away from the terminology management to the terminology leadership model.

In line with the need for transdisciplinary cooperation and networking in terminology work, and following the model of some European terminology institutions (particularly the Swedish terminology centreTerminologicentrum $T N C^{2}$ ), the Faculty of Philology, University of Belgrade is in the process of founding The Centre for terminology, translation and transdisciplinary studies. The idea behind the Centre is to, following the terminology leadership model, develop and maintain a network of terminologists from different professions, and coordinate the existing and forthcoming terminology-related projects and activities in the Serbian language through the activities of collecting, selecting, and harmonizing the terminology of individual fields, creating terminology resources (technical dictionaries, glossaries, lexicons, termbases, technical writing manuals, etc.), developing and using terminology management tools and systems, providing terminology services and support to organizations and individuals, providing training in terminology, technical writing, and professional translation, and cooperating with national and international language, terminology and standardization institutions. The terminology centre as such is expected to significantly contribute to the harmonization, systematization, and standardization of subject field terminologies and thus to the construction of a complete terminology infrastructure of the Serbian language.

\section{Conclusion}

The concept behind the term terminology management is not only ambiguous, but it also implies a hierarchical relationship between different actors and stakeholders. Terminology leadership, in contrast to terminology management (in its widest sense), puts emphasis on interdisciplinary and transdisciplinary networking, heterarhical relations, cooperation, and teamwork.

Two groups of respondents in two separate surveys, members of an academic community (management experts) and representatives of translators (language experts), both confirmed the need for networking, interdisciplinary and transdisciplinary cooperation and exchange of experiences in terminology work, thus indicating a shift from the application of terminology management (in its widest sense) to terminology leadership model in Serbian terminology planning for the subject field of management. Some of the replies, however, still indicate the strong influence of the standard lanuage culture, with the dominant traditional top down orientation in language and terminology planning, in which linguists are seen as exclusive language and terminology planners in a language community.

The results of the surveys thus indicate a growing need for revising and repositioning Serbian terminology planning for this subject field towards a more flexible and democratic leadership model, which would recognize both linguists and subject field experts as terminology decision-makers for this subject field to ensure its sustainable development and maintenance of professional discourse functionality in the Serbian language. In future, similar research should be carried out in subject fields to ensure that similar approach is acceptable across disciplines. If the results show similar tendencies, a step towards implementation of the terminology leadership model would be the work of the newly founded Centre for terminology, translation and transdisciplinary studies at the University of Belgrade. 


\section{REFERENCES}

[1] Andjelkovic, J. (2018). Terminologija menadžmenta: u prilog razvoju terminološke i jezičke politike i planiranja (unpublished doctoral thesis). Faculty of Philology, University of Belgrade, Serbia.

[2] Antia, B.E. (2000). Terminology and language planning: an alternative framework of practice and discourse. John Benjamins Co. Philadelphia: USA

[3] Bucher, A. L. (2007). Terminology work: The Swedish way. Terminologija,14, 37-48

[4] Bugarski, R. (2003). Jezici. Beograd: XX vek.

[5] Byrne, D. (2002). Complexity theory and the social sciences: An introduction. Rutledge.

[6] Clyne, M., \& Sharifian, F. (2008). English as an international language. Australian Review of Applied Linguistics, 31(3), 28-1.DOI: 10.2104/aral0828

[7] Eckert, P. \& McConnell-Ginet, S. (1992). Think practically and look locally: Language and gender as community-based practice. Annual Review of Anthropology. Palo Alto: Annual Reviews. 21:461-490. DOI: 10.1146/annurev.an.21.100192.002333

[8] Filipovic, J. (2009). Moć reči: Ogledi iz kritičke sociolingvistike. Beograd: Zadužbina Andrejević.

[9] Filipovic, J. (2012). Language policy and planning from the complexity perspective. U: Julijana Vuco, J. \& Filipovic, J.: Philological Research Today. Language and Society. Filološki fakultet: Beograd, 285320.

[10] Filipovic, J., \& Vuco, J. (2012). Language policy and planning in Serbia: language management and language leadership. Anali Filološkog fakulteta, 24: 9-32.

[11] Filipovic, J. (2015). Transdisciplinary Approach to Language Study. Palgrave Macmillan. DOI: $10.1057 / 9781137538468$

[12] Filipovic, J., Djordan, A. (2018). Terminološka politika i planiranje u Srbiji: interdisciplinarni pristup. Srpski jezik (paper accepted for publication)

[13] Fiser, D. (2008). Recent trends in the translation industry in Slovenia. The Journal of Specialised Translation, 10.Retrieved from http://www.jostrans.org/issue10/art_fiser.php

[14] Fulford, H., \& Granell-Zafra, J. (2005). Translation and technology: A study of UK freelance translators. The Journal of Specialised Translation, 4 (1).

[15] Gornostay, T. (2010, March). Terminology management in real use. In Proceedings of the 5th International Conference Applied Linguistics in Science and Education , 25-26. Retrieved from https://www.researchgate.net/profile/Tatiana_Gornostay/publication/236218911_Terminology_Management_in_Real_ Use/links/00b7d5171480061b1c000000/Terminology-Management-in-Real-Use.pdf

[16] Humbley, J. (2003). Metaphor and secondary term formation. Cahier du CIEL 2000-2003, 197 - 210.Retrieved from http://citeseerx.ist.psu.edu/viewdoc/download?doi=10.1.1.625.3801\&rep=rep1\&type=pdf\#page=197

[17] Jakic, G. (2014). Terminologija organizacionih nauka. Beograd:Fakultet organizacionih nauka

[18] Jernudd, B. (1993). Language planning from a management perspective: An interpretation of findings. Language conflict and language planning, 72, 133.

[19] Jernudd, B. (1997). New agencies in language planning." TermNext News, 56, 57, 14-17.

[20] Jernudd, B. H., \& Neustupný, J. V. (1987). Language planning: for whom. In Proceedings of the international colloquium on language planning (pp. 69-84). Québec: Les Presses de l'Université Laval.

[21] Lagoudaki, E. (2006). Translation memory systems: enlightening users' perspective; key findings of the TM survey 2006 carried out during July and August 2006. Retrieved from https://pdfs.semanticscholar.org/6c55/2454a3368e08cee7dc9a5fb3aa441a79db35.pdf

[22] Milroy, J. (2001). Language ideologies and the consequences of standardization. Journal of Sociolinguistics. 5 (4), 530-555. DOI: 10.1111/1467-9481.00163

[23] Neustupny, J., \& Jernudd, B. H. (1991). Multi-disciplined language planning. 29-36.

[24] Piper, P. (1998). O velikim i malim jezicima u svetlu lingvističke ekologije. Filološki pregled, 25(1), 6786.

[25] Ricento, T. ed. (2006). An Introduction to Language Policy: Theory and Method. Malden, MA, USA, Blackwell Publishing.

[26] Schaffner, C. (1999). Globalisation, Communication, Translation. Current Issues in Language \& Society, 6(2), 93-102.DOI: 10.1080/13520529909615538

[27] SDL software company (2018). Terminology Resource Hub. Retrieved from http://www.sdl.com/software-and-services/translation-software/terminology-management/terminology-resource-hub/.

[28] Spolsky, B. (2004).Language Policy. Cambridge: Cambridge University Press.

[29] Spolsky, B. (2009). Language Management. Cambridge: Cambridge University Press.

[30] Spolsky, B. (ed.). (2012). The Cambridge Handbook of Language Policy. Cambridge University Press. DOI: $10.1017 /$ CBO9780511979026

[31] Terminologicentrum TNC (2018). TNC, the Swedish Centre for Terminology Retrieved from http://www.tnc.se/om-tnc/in-english/ 
[32] UNESCO (2005). Guidelines for terminology policies: formulating and implementing terminology policies in language communities. United Nations: ParisUhl-Bien, M., Marion R. \& McKelvey, B. (2007). Complexity Leadership Theory: Shifting Leadership from the Industrial Age to the Knowledge Era. The Leadership Quarterly, 18/4: 298-318. DOI: 10.1016/j.leaqua.2007.04.002

[33] Uhl-Bien, M., Marion, R., \& McKelvey, B. (2007). Complexity leadership theory: Shifting leadership from the industrial age to the knowledge era. The leadership quarterly, 18(4), 298-318. DOI:10.1016/j.leaqua.2007.04.002

[34] Whitley, M.J. (2004). Leadership and the New Science. Discovering Order in a Chaotic World. San Francisco, CA: Berrett-Koehler Publishers Inc.

[35] Wright, S. E., G. Budin (1997). Handbook of Terminology Management -Volume 1: Basic Aspects of Terminology Management. Philadelphia, USA: John Benjamins Publishing Company

Received: 2018-02-07

Revisions requested: 2018-03-11

Revised: 2018-05-19

Accepted: 2018-08-30

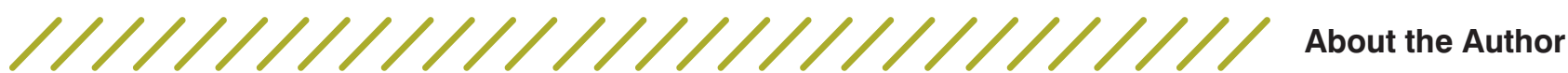

\section{Jelena Anđelković \\ University of Belgrade, Faculty of Organizational Sciences, Serbia plecasj@fon.bg.ac.rs}

Jelena Anđelković is a Teaching Assistant at the Faculty of Organizational Sciences, University of Belgrade, with a PhD in linguistics. Her academic and research interests include languages for specific purposes, corpus linguistics, terminology language policy and planning, and terminology management.

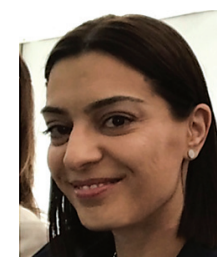

\section{Jelena Filipović}

University of Belgrade, Faculty of Philology, Serbia jelenafbgd@gmail.com

Jelena Filipović is a Professor of the Spanish language and Sociolinguistics and the Vice-Dean for Scientific Development at the Faculty of Philology, University of Belgrade. Her academic interests include sociolinguistics, critical sociolinguistics, Sephardic studies, Hispanic linguistics, applied linguistics, and language policy and planning.

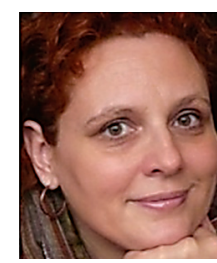

